\title{
Site-Dependent Tension Properties of Inertia Friction-Welded Joints Made From Dissimilar Ni-based Superalloys
}

\author{
O.N. Senkov, D.W. Mahaffey, S.L. Semiatin, and C. Woodward
}

\author{
(Submitted September 3, 2014; in revised form December 17, 2014; published online January 6, 2015)
}

\begin{abstract}
Microstructure, tensile properties, and fracture behavior of the inertia friction weld joints of dissimilar superalloys, cast Mar-M247 and wrought LSHR, were studied to assess the weld quality. Tensile tests were conducted at 23 and $704{ }^{\circ} \mathrm{C}$ on the samples containing different areas of the weld interface of the same welded material. The stress-strain curves were registered at different axial distances from the weld interface. In all tested samples, plastic deformation was localized on Mar-M247 side, outside the heat-affected zone (HAZ), and the resistance to plastic deformation of Mar-M247 increased with a decrease in the distance from the weld interface inside HAZ. Only elastic deformation occurred on the LSHR side. Fracture occurred on the Mar-M247 side, outside HAZ, or at the weld interface. In the latter case, welding defects in the form of clusters of nanometer-sized oxide and carbide particles were observed at the fracture surfaces. These results revealed that the IFW process is capable of producing the weld joints between Mar-M247 and LSHR with the fracture strength higher than that of Mar-M247. However, optimization of the IFW processing parameters is required to minimize clustering of oxide/carbide particles at the weld interface in this alloy pair.
\end{abstract}

Keywords inertia friction welding, LSHR, Mar-M247, microstructure, $\mathrm{Ni}$ superalloy, tension properties, welding defects

\section{Introduction}

Nickel-based superalloys are among the most important structural materials for use in high temperature applications (Ref 1). Fine-grained wrought and/or powder metallurgy (PM) superalloys, such as IN100 or LSHR, possess high strength at temperatures $\leq 700-760{ }^{\circ} \mathrm{C}$, but have insufficient creep resistance at higher temperatures. Single-crystal or coarse-grained cast superalloys, such as CMSX-10 or Mar-M247, have outstanding creep resistance at temperatures $\leq 1000{ }^{\circ} \mathrm{C}$, but have almost half the tensile strength of the PM superalloys below 700-800 ${ }^{\circ} \mathrm{C}$ (Ref 2, 3). Several advanced applications require different sections of a single structure to operate in very different temperature and loading conditions. An attractive way to fulfill this requirement is to join different superalloys in one structure (Ref 4). In such a structure, sections operating under high loading conditions, but at lower temperatures, are made of a PM/wrought alloy, while sections requiring outstanding creep resistance at higher temperatures are made of a cast alloy.

O.N. Senkov, D.W. Mahaffey, S.L. Semiatin, and C. Woodward, Air Force Research Laboratory, Materials and Manufacturing Directorate, Wright-Patterson Air Force Base, OH 45433. Contact e-mail: oleg.senkov.ctr@us.af.mil.
Solid-state friction welding processes, including inertia friction welding (IFW), are considered suitable for joining Ni-based superalloys, as solidification-related defects inherent to fusion welding can be avoided (Ref 5-7). Indeed, the IFW process was successfully used to join wrought superalloys such as IN718, RR1000, and 720Li (Ref 7-10). Unfortunately, no reports are yet available on using the IFW process to weld cast superalloys, although a partially successful attempt was made to join these hard-to-weld alloys by linear friction welding (Ref 11). Only two publications report friction welding of cast superalloys to PM/wrought superalloys (Ref 12, 13).

IFW was recently used to join a cast Mar-M247 to a forged PM LSHR, and the microstructure, chemical composition, and microhardness of the welded material were determined and correlated to the welding parameters (Ref 13). These alloys are considered as candidate superalloys for an advanced hybrid turbine disk (Ref 4). Tensile strength of both alloys is mainly controlled by $\gamma^{\prime}$ particles and also enhanced by solid solution and grain boundaries. Having much finer $\gamma$ grains and $\gamma^{\prime}$ precipitates, LSHR has almost twice the strength of Mar-M247 at temperatures below $700{ }^{\circ} \mathrm{C}$. However, the strength of LSHR rapidly decreases at higher temperatures and above $\sim 900$ $1000{ }^{\circ} \mathrm{C}$ Mar-M247 becomes stronger than LSHR (Ref 4, 14-16). Considerable high temperature softening of LSHR, relative to Mar-M247, is caused by a lower $\gamma^{\prime}$ solvus temperature of LSHR, $T_{\mathrm{LS} \mathrm{S}}=1157{ }^{\circ} \mathrm{C}$ (Ref 17), than that of Mar-M247, $T_{\mathrm{M} \mathrm{S}}=1225^{\circ} \mathrm{C}(\operatorname{Ref} 18)$ and, at low strain rates, by grain-boundary sliding in the fine-grained LSHR. As a result, during the IFW process, which occurred above $T_{\mathrm{LS} \text { S }}$ but below $T_{\mathrm{M} \text { S }}$ (Ref 13), LSHR was softer than Mar-M247 and showed extensive local upset at the joint surface under the applied compression force. Extensive radial flow of the joining material flushes oxides and other contaminants from the joining 
surfaces toward a flash beyond the original outer diameter and is considered to be beneficial for producing sound metallurgical bonding during IFW (Ref 6, 19). Unfortunately, sluggish radial plastic flow of Mar-M247 during IFW hindered self-cleaning of the mating surfaces from friction- and environment-induced contaminants. Several primary IFW tests with different processing parameters were carried out in effort to develop a suitable welding process and to fabricate a sound bond of these two alloys (Ref 13).

The objective of the present work is to assess the weld quality of the IFW joints of the Mar-M247 and LSHR alloys produced under the recently developed processing parameters (Ref 13) and to identify the welding defects liable for the joint weakening. Microstructure, tensile properties, and fracture behavior of the samples containing different areas of the weld interface of the same welded material were studied and defects responsible for the fracture during tensile testing were identified. Tensile tests of as-welded samples were conducted at room temperature, in accord to the ANSI/AWS B4.0 standard (Ref 20) and stressstrain curves were registered at different axial distances from the weld interface, with the spatial resolution of $1 \mathrm{~mm}$, using image correlation software. Additional tensile tests were also conducted at $704{ }^{\circ} \mathrm{C}$, which is representative of a turbine operation temperature (Ref 4$)$. The tensile properties and fracture behaviors of the IFW joints were compared with those of the parent alloys.

\section{Experimental Procedures}

Cylindrical samples of forged PM LSHR and directionally solidified Mar-M247 alloys were joined by IFW using the IFW process conditions identified in (Ref 13). Namely, the moment of inertia and maximum rotation speed of flywheel were $I=0.379 \mathrm{kgm}^{2}$ and $\omega_{\mathrm{o}}=346 \mathrm{rad} / \mathrm{s}$, respectively, and the axial force under which the welding surfaces were brought into contact was $P=55.2 \mathrm{kN}$. The compositions of the alloys are given in Table 1. The diameter and the length of the weld samples were 12.7 and $100 \mathrm{~mm}$, respectively. Dog-bone-like tension specimens with the gage length of $20 \mathrm{~mm}$ and the gage cross section of $1.2 \mathrm{~mm} \times 3.5 \mathrm{~mm}$ were extracted from the weld samples. The extraction plan is schematically shown in Fig. 1(a) and images of non-deformed and deformed tensile specimens are shown in Fig. 1(b). The weld interface was in the middle of the gage section, perpendicular to the tension direction. Parallel gridlines made of a thin carbon film covered the flat surfaces of the specimens. The gridlines were perpendicular to the tension direction and their spacing was $1.0 \mathrm{~mm}$. Two series of specimens were used. Tension specimens of series \#1 were extracted from the well-welded middle regions of the IFW samples. Tension specimens of series \#2 were extracted from the rim sections of the same IFW samples and contained clusters of carbide and oxide nano-particles at the weld interface. Tension tests were conducted at room temperature (RT) and $704{ }^{\circ} \mathrm{C}$, at a constant ram speed of $0.02 \mathrm{~mm} / \mathrm{s}$ using an MTS hydraulic machine. The macroscopic (on 7- and 16-mm-long sections) and local (on 1mm-long sections between the gridlines, at different axial distances from the weld interface) stress-strain curves were registered with the use of a Vic-Gauge software (Correlated Solutions, Inc. Columbia, SC, USA). Scanning electron microscopy (SEM) techniques were used to study the microstructure of the tested samples. Microhardness was measured at different distances from the weld interface using a Vickers microhardness tester under $500 \mathrm{~g}$ load exposed for $20 \mathrm{~s}$.

Table 1 Average compositions (in wt.\%) of LSHR and Mar-M247 alloys

\begin{tabular}{llllllllllllll}
\hline & Al & B & C & Co & Cr & Hf & Mo & Nb & Ti & Ta & W & Zr & Ni \\
\hline LSHR & 3.17 & 0.03 & 0.03 & 21.4 & 12.3 & 0.06 & 2.66 & 1.45 & 3.48 & 1.58 & 4.48 & 0.05 & 49.3 \\
Mar-M & 5.10 & $\cdots$ & 0.07 & 10.4 & 8.51 & 1.49 & 0.73 & 0.00 & 0.94 & 2.64 & 10.0 & 0.01 & 60.0 \\
\hline
\end{tabular}
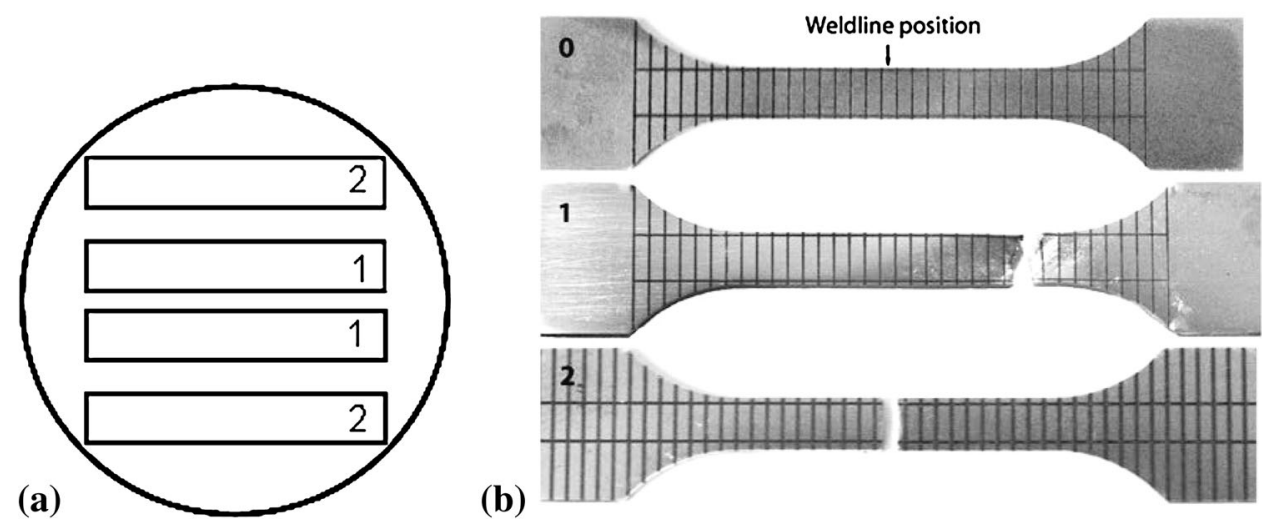

(b)

\section{Results}

\subsection{Microstructure and Properties of Alloys in As-received Condition}

A forged LSHR alloy used in this work has a fine-grained duplex microstructure consisting of the mixture of equiaxed $\gamma$ 

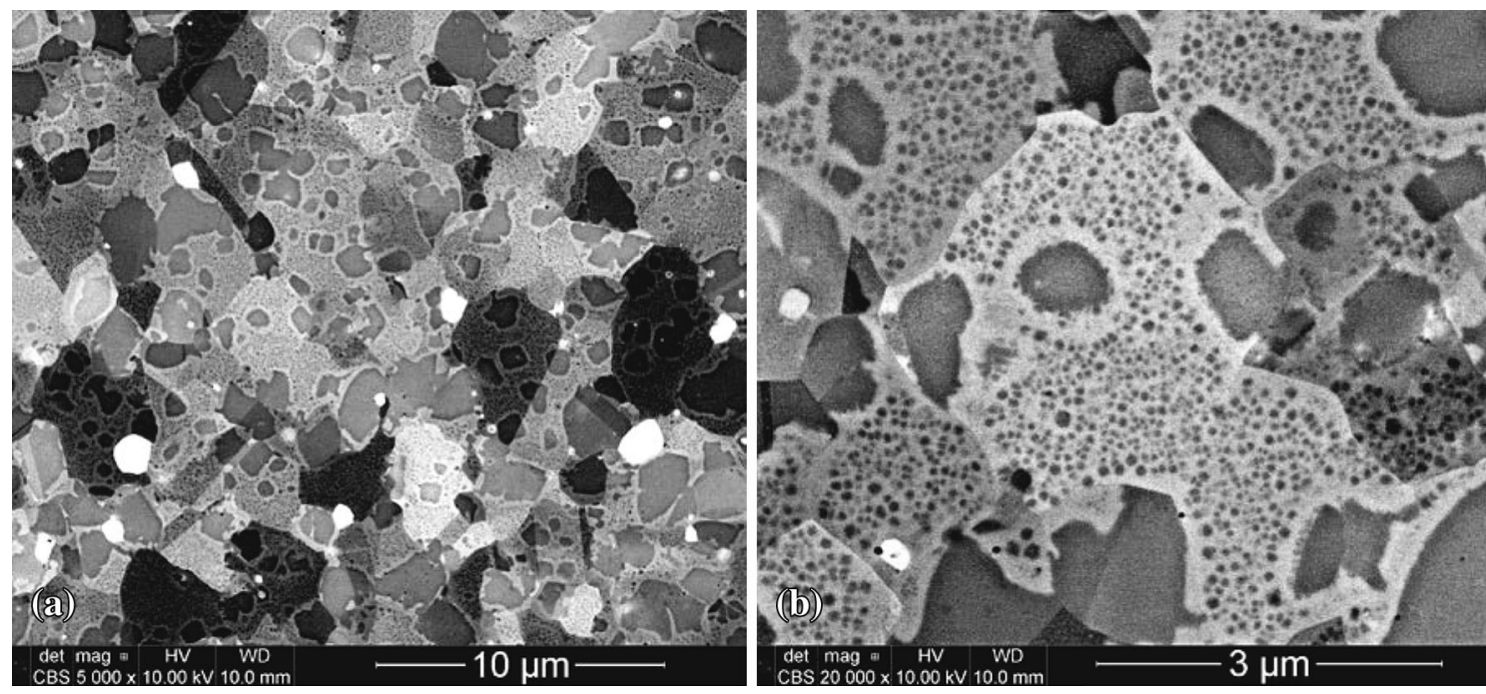

Fig. 2 Microstructure of the LSHR alloy before inertia friction welding. (a) Equiaxed matrix $\gamma$ grains, large blocky primary $\gamma^{\prime}$ particles inside the grains and at grain boundaries (they have a darker color than the matrix) and carbide particles (bright color). (b) A magnified region showing fine spherical secondary $\gamma^{\prime}$ particles inside the matrix grains, as well as larger primary $\gamma^{\prime}$ particles. BSE images

Table 2 Tension properties of the LSHR and Mar-M247 alloys at $T=23{ }^{\circ} \mathrm{C} / 704{ }^{\circ} \mathrm{C}$

\begin{tabular}{lllll}
\hline Alloy & $\boldsymbol{E}, \mathbf{G P a}$ & $\boldsymbol{\sigma}_{\mathbf{0 . 2}}, \mathbf{M P a}$ & $\boldsymbol{\sigma}_{\mathbf{u}}, \mathbf{M P a}$ & $\boldsymbol{\delta}, \boldsymbol{\%}$ \\
\hline LSHR & $220 / 220$ & $1165 / 1070$ & $1575 / 1320$ & $13 / 16$ \\
Mar-M247 & $185 / 178$ & $703 / 662$ & $859 / 724$ & $8.2 / 2.1$ \\
\hline
\end{tabular}

grains, primary $\gamma^{\prime}$ particles and fine carbide particles (Fig. 2a). The average sizes of $\gamma$ grains, primary $\gamma^{\prime}$ particles, and carbide particles are $\sim 3.5,1.3$, and $0.7 \mu \mathrm{m}$, respectively. The volume fraction of primary $\gamma^{\prime}$ is $\sim 35 \%$ and that of carbide particles is $\sim 1.0 \%$. Fine, nanometer-sized secondary $\gamma^{\prime}$ particles are also present inside the $\gamma$ grains (Fig. 2b), and the total volume fraction of the $\gamma^{\prime}$ phase is $\sim 55 \%$ (Ref 13, 17). Tensile properties of the as-received LSHR are given in Table 2. At (RT, $T=23{ }^{\circ} \mathrm{C}$ ), LSHR has yield strength, $\sigma_{0.2}$, of $1165 \mathrm{MPa}$, ultimate tension strength, $\sigma_{\mathrm{u}}$, of $1575 \mathrm{MPa}$, elongation, $\delta$, of $13 \%$ and elastic modulus, E, of $220 \mathrm{GPa}$. An increase in the testing temperature to $704{ }^{\circ} \mathrm{C}$ results in a slight decrease in strengths $\left(\sigma_{0.2}=1070 \mathrm{MPa}, \sigma_{\mathrm{u}}=1320 \mathrm{MPa}\right)$ and an increase in tensile ductility $(\delta=13 \%$ ), while $E=220 \mathrm{GPa}$ is the same as at RT. These properties of LSHR are in good agreement with previously reported data $(\operatorname{Ref} 4,14,15,21)$. Vickers microhardness of LSHR is $465 \mathrm{Hv}$.

The microstructure of cast Mar-M247 consists of coarse, $>1 \mathrm{~mm}$ in diameter, dendritic $\gamma$ grains, and irregular-shaped carbide particles (Fig. 3a). The carbide particles are homogeneously distributed in the alloy at the volume fraction of $\sim 1.7$ $2 \%$, and their average size is $\sim 15 \mu \mathrm{m}$; however, some carbide particles can be as large as $30 \mu \mathrm{m}$ (see Fig. 8). Cuboidalshaped primary $\gamma^{\prime}$ particles, which size is $\sim 1.25 \mu \mathrm{m}$ and volume fraction is $\sim 64 \%$ are present inside the $\gamma$ matrix (Fig. 3b). Tensile properties of the cast Mar-M247 samples are given in Table 2. At RT, the alloy has $E=185 \mathrm{GPa}, \sigma_{0.2}=703$ $\mathrm{MPa}, \sigma_{\mathrm{u}}=859 \mathrm{MPa}$, and $\delta=8.2 \%$. At $T=704{ }^{\circ} \mathrm{C}$, it shows $E=178 \mathrm{GPa}, \sigma_{0.2}=662 \mathrm{MPa}, \sigma_{\mathrm{u}}=724 \mathrm{MPa}$, and $\delta=2.1 \%$. Although the $E$ values are in agreement with the earlier reports
(Ref 16, 21), the $\sigma_{0.2}$ and $\sigma_{\mathrm{u}}$ values of the Mar-M247 used in this work are noticeably lower than the standard properties of this alloy (e.g., $\sigma_{0.2}=815 \pm 20 \mathrm{MPa}$ and $\sigma_{\mathrm{u}}=965 \pm 35 \mathrm{MPa}$ at $\left.23{ }^{\circ} \mathrm{C}\right)(\operatorname{Ref} 4,16,21)$. The reduced strength values are due to the as-cast condition of the alloy, with coarse grains of the $\gamma$ matrix and large $\gamma^{\prime}$ particles. Vickers microhardness of MarM247 is $\sim 400 \mathrm{Hv}$.

\subsection{Microstructure and Properties of Inertia Friction-Welded Specimens}

Detailed description of the microstructure of the inertia friction-welded LSHR/Mar-M247 alloy samples is given in Ref 13 . Here a brief description is given for a complete picture. The IFW process results in a sharp weld interface between these two alloys. Figure 4 illustrates the microstructure of two distinct regions of the weld interface between LSHR and MarM247 alloys. Due to different compositions, the alloys are well recognized on the electron backscatter images by their different gray levels. Namely, LSHR is noticeably darker than MarM247. In the center and middle sections of the welded samples, the weld line is wavy and mainly free of welding defects (Fig. 4a), while near the sample outer surface it appears more linear and clusters of oxide and/or carbide nano-particles can be found there as the main welding defects (Fig. 4b). Heataffected zones (HAZs), within which the microstructure and microhardness of the welded alloys are different from the respective non-processed alloys, are recognized on both sides of the weld interface (Fig. 5). Thickness of HAZ is $\sim 2.5 \mathrm{~mm}$ on the LSHR side and $\sim 3.0-4.0 \mathrm{~mm}$ on the Mar-M247 side. Inside the HAZ, the average $\gamma$ grain size and the size and volume fraction of primary $\gamma^{\prime}$ particles gradually decrease, while microhardness increases, with a decrease in the distance L from the weld interface, both on the LSHR and Mar-M247 sides (Fig. 5a and b, respectively). Moreover, cuboidal shapes of primary $\gamma^{\prime}$ particles in Mar-M247 change to elliptical or spherical with a decrease in the particle size closer to the weld interface (Fig. 4). Primary $\gamma^{\prime}$ are absent and microhardness approaches its maximum value of $\mathrm{Hv}=565 \pm 10$ within a 60 to $100 \mu \mathrm{m}$ thick region at the weld interface on the LSHR side. 

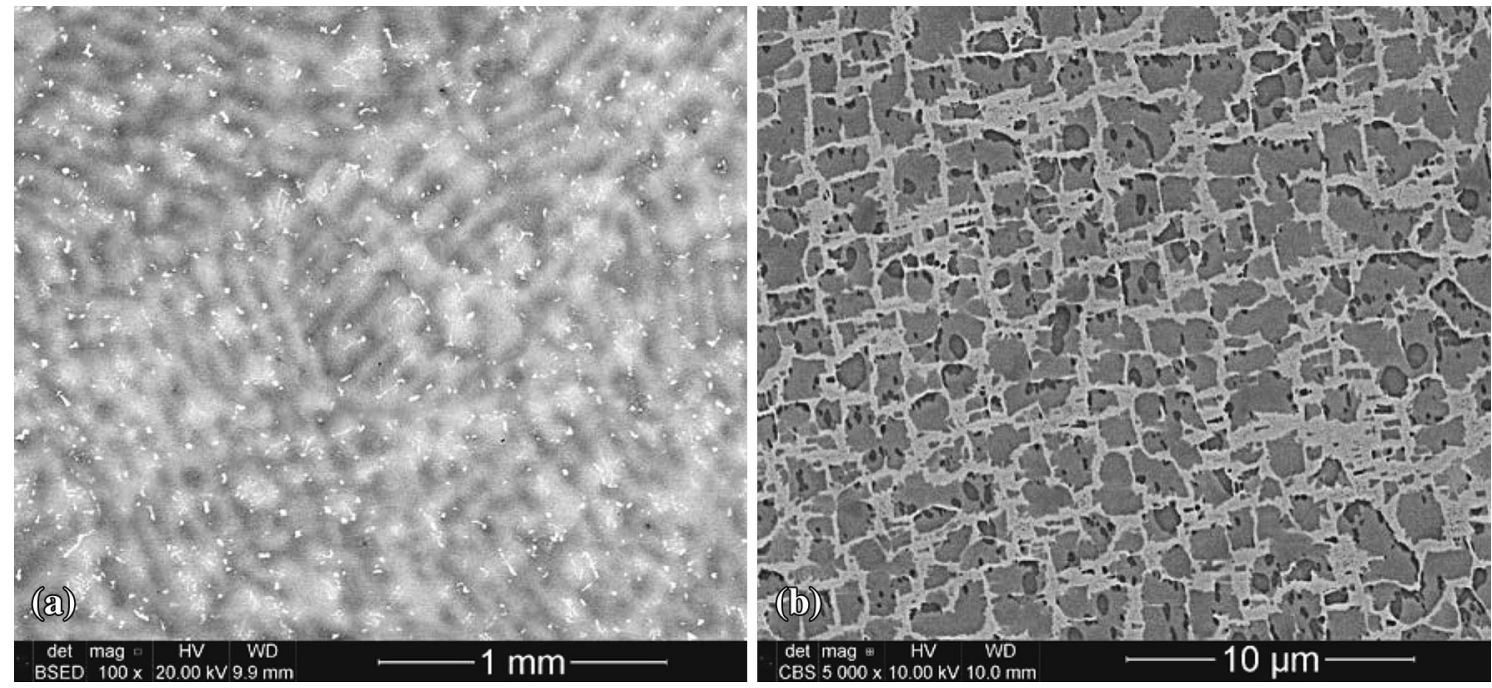

Fig. 3 Microstructure of the Mar-M247 alloy before inertia friction welding. (a) Large dendritic $\gamma$ grains decorated with bright carbide particles. (b) Cuboidal-shaped primary $\gamma^{\prime}$ particles inside the $\gamma$ grains. BSE images
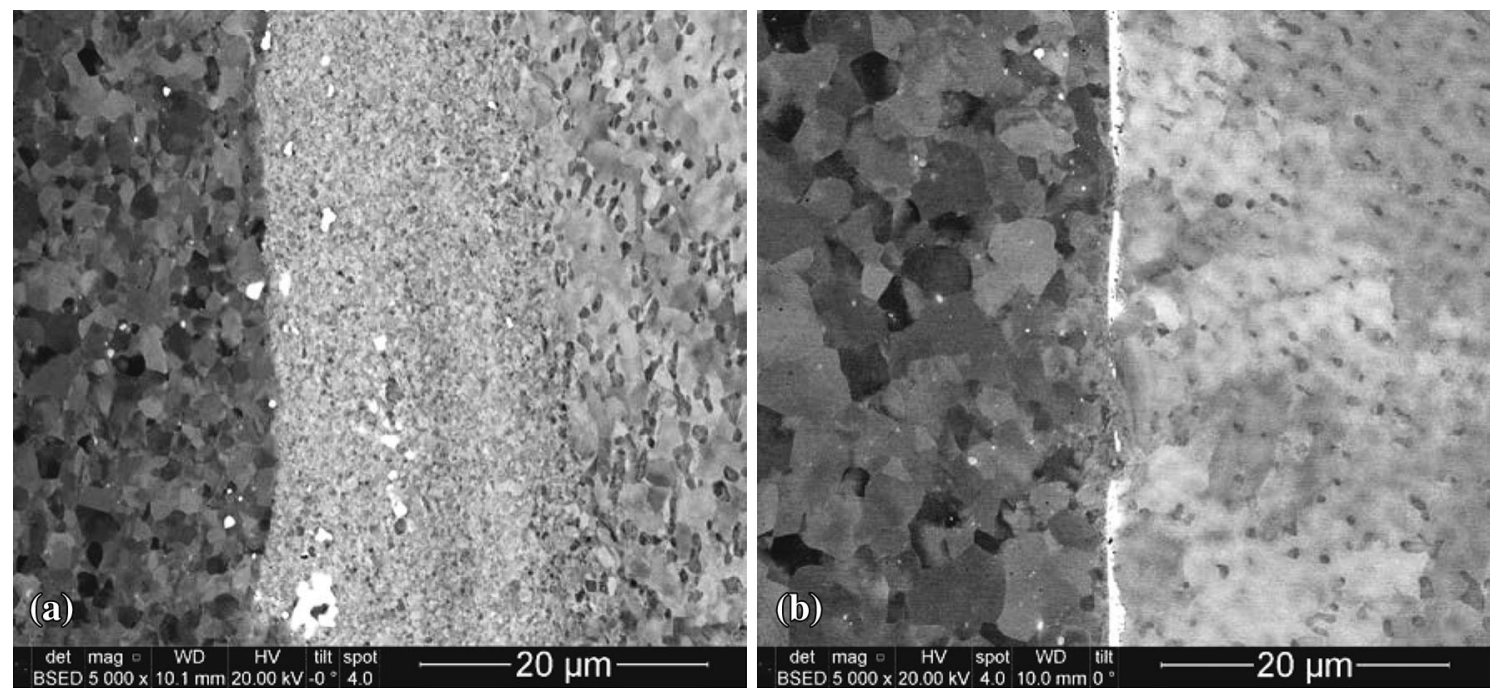

Fig. 4 Backscatter SEM images of the weld interface regions between Mar-M247 (lighter intensity, on the right) and LSHR (darker intensity, on the left) alloys. (a) The interface with no welding defects and (b) the interface region containing welding defects in the form of agglomerated nano-particles of oxides and carbides

The average LSHR grain size in this region is $1.8 \pm 0.3 \mu \mathrm{m}$. A 5 to $30 \mu \mathrm{m}$ thick layer with submicron-sized grains, inside which no primary $\gamma^{\prime}$ particles are detected, is present on the Mar-M247 side adjacent to the interface (Fig. 4a). Mar-M247 approaches maximum microhardness $(\mathrm{Hv}=560 \pm 15)$ inside this layer. Noticeable spread of Mar-M247 microhardness is seen with a decrease in the distance from the weld interface (Fig. 5b). This microhardness variation is likely due to very non-homogeneous deformation of this alloy during IFW (Ref 13). The average grain size of LSHR is larger and the layer with nano-sized grains at the weld interface on the MarM247 side becomes thinner or not present at all at the interface regions with the welding defects (Fig. 4b). Apparently, these regions, located near the outer surface, did not experience considerable plastic deformation and dynamic recrystallization as other welded regions.
To estimate the weld quality, tensile tests of specimens containing different regions of the weld interface were conducted at room temperature, in accord to the ANSI/AWS B4.0 standard (Ref 20), as well as at $T=704{ }^{\circ} \mathrm{C}$, which is representative of a turbine operation temperature (Ref 4). The stress-strain curves registered from different-scale gage lengths and representing the behavior of (i) a whole sample containing the weld interface in the middle of the gage section, (ii) only Mar-M247 side, or (iii) only LSHR side are given in Fig. 6. Tensile properties are summarized in Table 3.

During testing at RT, tensile specimens of series \#1 (i.e., those extracted from the middle regions of the IFW samples) show $E=198 \mathrm{GPa}, \sigma_{0.2}=727 \mathrm{MPa}, \sigma_{\mathrm{u}}=869 \mathrm{MPa}$ and $\delta=5.0 \%$, and they fracture on the Mar-M247 side, outside HAZ. Only elastic deformation, with $E=220$ GPA, occurs on the LSHR side, apparently because the ultimate tensile strength 

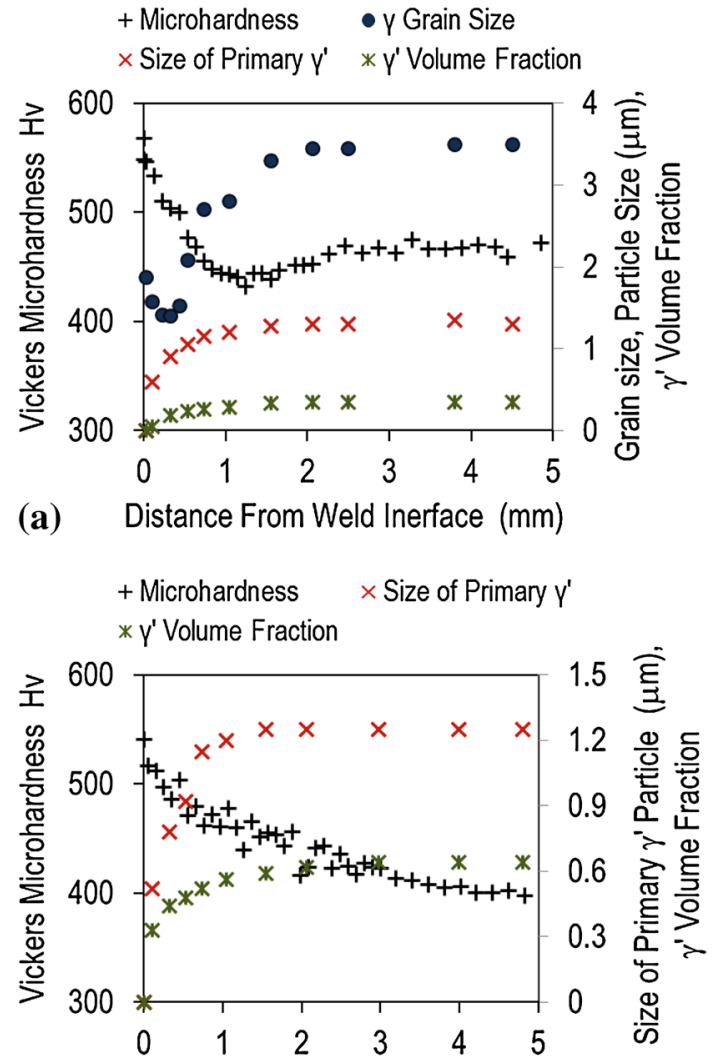

(b) Distance From Weld Inerface $(\mathrm{mm})$

Fig. 5 Dependences of the Vickers microhardness, $\gamma$ grain size, size of the primary $\gamma^{\prime}$ particles, and volume fraction of the $\gamma^{\prime}$ particles on the distance from the weld interface: (a) LSHR alloy side and (b) Mar-M247 alloy side. Measurements were conducted in the weld region similar to shown in Fig. 4(a)

of the welded specimens is below the yield strength of LSHR (see Tables 2 and 3). At the same time, the Mar-M247 side shows extended plastic deformation, with $\delta=10.6 \%$, $E=180 \mathrm{GPa}, \sigma_{0.2}=710 \mathrm{MPa}$, and $\sigma_{\mathrm{u}}=869 \mathrm{MPa}$ (Fig. 6a; Table 3). By knowing the reduction in the cross section area of the fracture region, $\lambda=0.164$, the true fracture stress $\sigma_{\mathrm{f}}=1039 \mathrm{MPa}$, of Mar-M247 is estimated using the following relation: $\sigma_{\mathrm{f}}=\sigma_{\mathrm{u}} /(1-\lambda)$.

The RT elastic modulus and yield strength of tensile specimens of series \#2 (i.e., those extracted from the rim sections of the IFW samples) are almost the same as the respective properties of specimens of series \#1 (Table 3); however, $\sigma_{\mathrm{u}}$ and $\delta$ values are lower, $850 \mathrm{MPa}$ and $2.9 \%$, respectively. The Mar-M247 side of these specimens shows $E=180 \mathrm{GPa}$ and $\sigma_{0.2}=695 \mathrm{MPa}$, and attains $\sigma_{\mathrm{u}}=850 \mathrm{MPa}$ and $\delta=6.1 \%$ at the time of premature fracture at the weld interface. No plastic deformation occurs on the LSHR side (Fig. 6b).

Local deformation behavior (within 1-mm gage spacing) at the Mar-M247 side is noticeably different from the average behavior described above. First, extensive localization of the plastic deformation outside the HAZ is recognized (Fig. 7a). Maximum local elongations of 21 and $9.0 \%$ are observed in specimens of series $\# 1$ and $\# 2$, respectively, at the same distance, $L=5.5 \mathrm{~mm}$, from the weld interface. Second, the local yield strength of Mar-M247 increases considerably near the weld interface (Fig. 7b). For example, at $L=0.5 \mathrm{~mm}$, $\sigma_{0.2}=840 \mathrm{MPa}$ and $788 \mathrm{MPa}$ for the specimens of series \#1 and \#2, respectively. Finally, specimens of both series show similar strain hardening behavior (Fig. 7c). The local strain hardening coefficient, $\gamma_{\varepsilon}=\left(\sigma_{\mathrm{u}}-\sigma_{0.2}\right) /\left(\varepsilon_{\mathrm{u}}-0.002\right)$, has a minimum of $1.4 \pm 0.3 \mathrm{GPa}$ in the strain localization region and it increases with a decrease in the distance from the weld interface, approaching the value of $6.9 \pm 0.5 \mathrm{GPa}$ at $L=0.5$ $\mathrm{mm}$. The similar strain hardening behavior and almost the same values of the yield strength on the Mar-M247 side of the weld specimens of series $\# 1$ and $\# 2$ allow us to suggest that the observed reduced $\sigma_{u}$ and $\delta$ values of this side for the series \#2 are caused by premature fracture at a weaker weld interface rather than the result of different microstructure of the alloy itself.

Figure 6(c) and (d) illustrate the deformation behavior of welded specimens of series \#1 and \#2, respectively, during tensile testing at $T=704{ }^{\circ} \mathrm{C}$. Similar to the testing at RT, welded specimens of series \#1 deform plastically on the MarM247 side and elastically on the LSHR side, and their fracture occurs in the strain localization region on the Mar-M247 side outside HAZ. The elevated temperature tensile properties of the Mar-M247 side of these welded specimens are similar to the properties of non-welded alloy (compare Tables 2 and 3). Tensile elongation of the welded specimens is approximately half of that of the Mar-M247 side, because of no contribution from the LSHR side. An increase in the testing temperature from RT to $704{ }^{\circ} \mathrm{C}$ changes the deformation behavior of specimens of series \#2 dramatically (compare Fig. 6b and d). Very little plastic deformation is observed on the Mar-M side and the specimens fracture at the weld interface before the macroscopic yielding occurs, showing the fracture stress, $\sigma_{\mathrm{f}}=600 \mathrm{MPa}$.

\subsection{Microstructure of the IFW Specimens after Room Temperature Deformation}

After RT deformation of the welded specimen of both series, the microstructure of the LSHR side was similar to that before deformation, which is expected, as this side deformed only elastically. The morphology, size, and volume fraction of the $\gamma$ grains and $\gamma^{\prime}$ particles in the Mar-M247 side also did not change. For example, Fig. 8(a) shows a dendritic structure of the Mar-M247 alloy side of a series \#1 specimen after RT tensile deformation. Within the sample area from the weld interface on the left to the fracture surface on the right, the dendritic structure is the same and similar to those shown in Fig. 3(a) for the as-received alloy. Nonetheless, the RT plastic deformation leads to multiple fractures of virtually all large $(>2 \mu \mathrm{m})$ carbide particles along the whole gage section in the Mar-M247 side (see Fig. 8b and c). Cracks inside these particles are oriented nearly perpendicular to the tension direction. They generally do not propagate inside the $\gamma$ matrix, which is a strong indication that the fracture strength of the carbide particles is considerably lower than the strength of the matrix. Therefore, the alloy regions with high local density of these particles can be weakened by the carbide particle cracking during deformation, which can result in strain localization and macroscopic fracture.

Figure 9 shows the weld interface between the LSHR and Mar-M247 in a tensile specimen of series \#1. The weld interface is free of any welding defects. No cracks or porosity is developed at the weld interface during RT deformation either. 

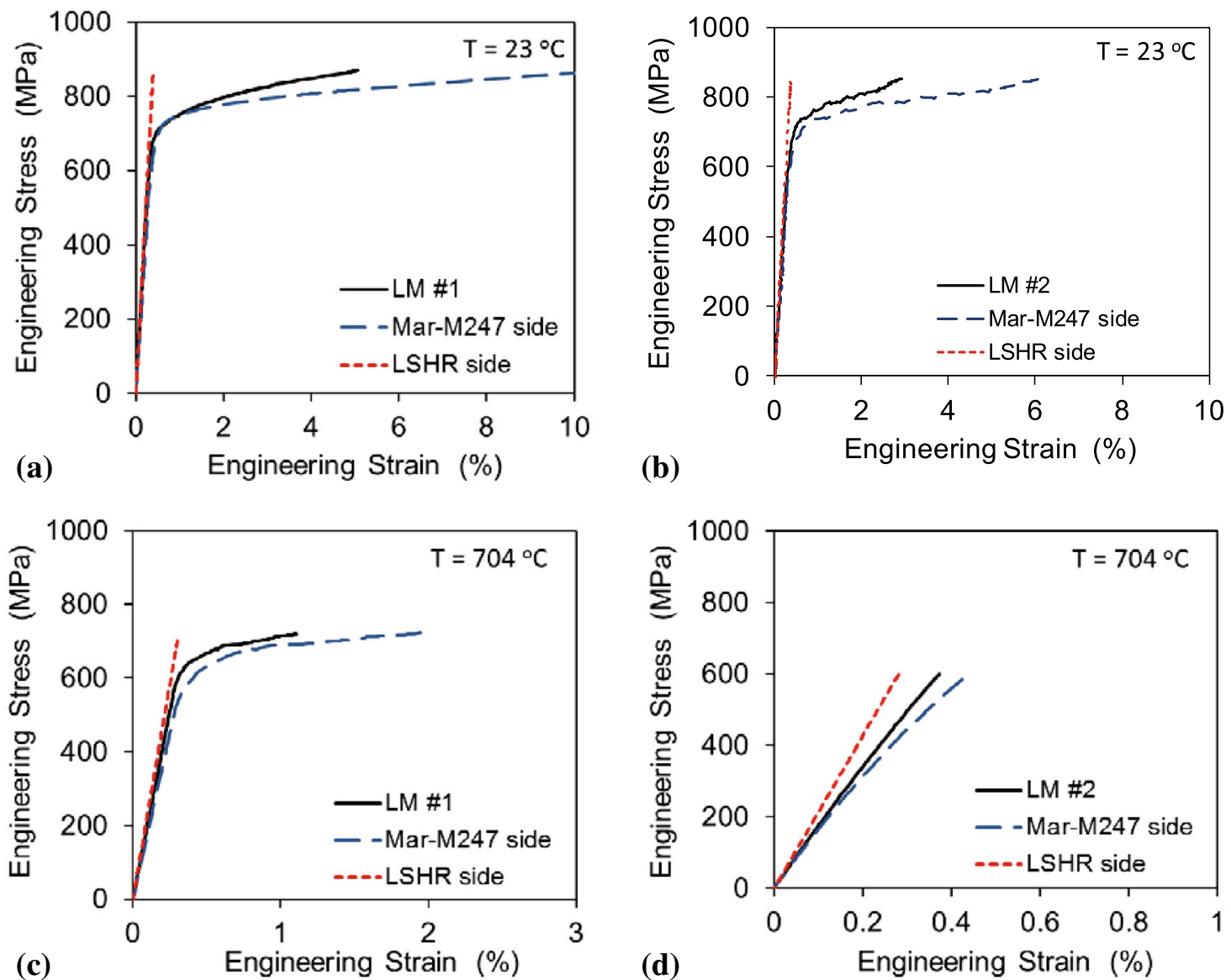

Fig. 6 Tensile stress-strain curves for the weld samples tested at (a, b) $23{ }^{\circ} \mathrm{C}$ and (c, d) $704{ }^{\circ} \mathrm{C}$. Samples LM \#1 (a, c) fractured on the MarM247 side and samples LM \#2 (b, d) fractured at or near the IFW interface. In each figure, the stress-strain curves are given for a 16-mm-long composite section containing the weld interface in the middle of the section (solid line); 7-mm-long section of the Mar-M247 side (blue dashed line); and 7-mm-long section of the LSHR side (red dotted line)

Table 3 Tension properties of the IFW Mar-M247/LSHR specimens at $T=23{ }^{\circ} \mathrm{C} / 704{ }^{\circ} \mathrm{C}$

\begin{tabular}{|c|c|c|c|c|}
\hline Sample ID & $E, \mathbf{G P a}$ & $\sigma_{0.2}, \mathrm{MPa}$ & $\sigma_{u}, \mathrm{MPa}$ & $\delta, \%$ \\
\hline$\# 1$ (a) & $180 / 181$ & $710 / 642$ & $869 / 724$ & $10.6 / 2.0$ \\
\hline$\# 1$ (b) & $220 / 223$ & $\ldots$ & $\ldots$ & $0.39 / 0.32$ \\
\hline$\# 1$ (c) & $198 / 204$ & $730 / 676$ & $869 / 724$ & $5.0 / 1.0$ \\
\hline$\# 2$ (a) & $180 / 167$ & $695 / \cdots$ & $850 / \cdots$ & $6.1 / 0.44$ \\
\hline$\# 2$ (b) & $223 / 214$ & $\cdots$ & $\cdots / \cdots$ & $0.38 / 0.28$ \\
\hline$\# 2$ (c) & $196 / 182$ & $727 / \cdots$ & $850 / \cdots$ & $2.9 / 0.37$ \\
\hline
\end{tabular}

The properties were measured ( $a, b$ ) within 7-mm-long gage sections of (a) Mar-M247 and (b) LSHR sides and (c) within the 16-mm-long gage section, with the weld interface in the middle of the section

The weld interface in this specimen looks similar to the weld interface area shown in Fig. 4(a) and it contains all the microstructural features described earlier in respect to Fig. 4(a). Fracture of this tensile specimen occurred in the Mar-M247 region, outside the HAZ (Fig. 8a). The crack has a jagged appearance and a number of carbide particles are seen on the fracture surface (Fig. 10). This observation suggests that fracture of welded specimens of series \#1 during RT tension deformation occurs by confluence of cracks initiated inside the carbide particles in the strain localization Mar-M247 region.

Scanning electron microscopy images of the fracture surface of a series \#1 specimen are shown in Fig. 11. The fracture surface has blocky, faceted, and layered (sedimentary) appearance (Fig. 11a, b), revealing weak $\{100\}$ crystallographic planes in the Mar-M247 alloy (Ref 21). This type of fracture is typical to the cast $\mathrm{Ni}$ superalloys, (Ref 22, 23). Cleaved surfaces of large fractured carbide particles are also observed in noticeable amounts, supporting our earlier suggestion that these particles are probably responsible for the fracture of the MarM247 alloy. The presence of shallow dimples on the faceted surfaces (Fig. 11c) reveals the ductile failure mechanism of the $\gamma$ matrix by cavitation. The size and morphology of the dimples are similar to those of the primary $\gamma^{\prime}$ particles. It is apparent that the dimples were formed due to extensive plastic deformation 

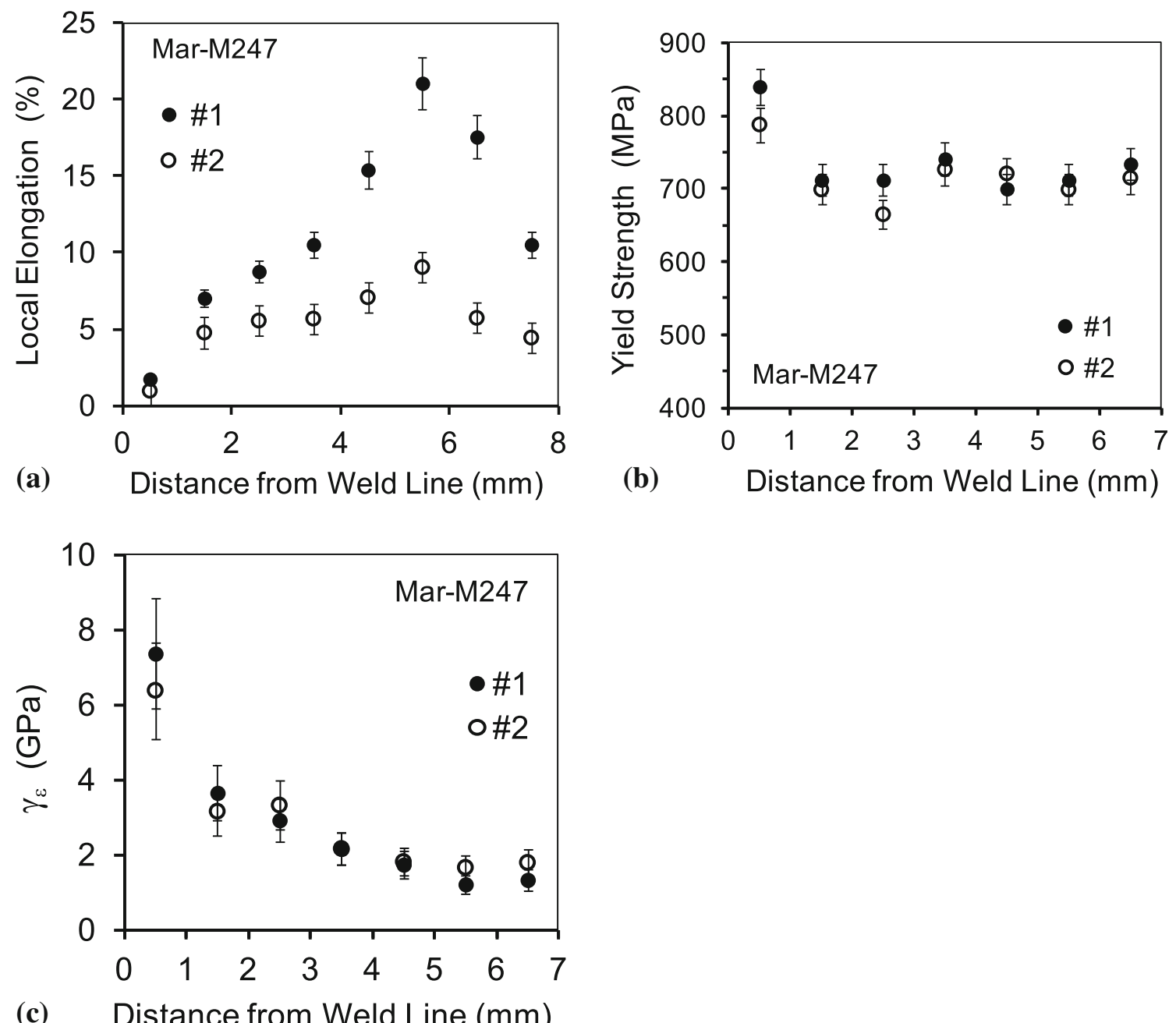

Fig. 7 Dependence on the distance from the weld interface of (a) the local elongation, (b) yield strength, and (c) strain hardening coefficient, $\gamma_{\varepsilon}$, in the Mar-M247 side of the welded specimens of series \#1 and \#2 (c). The quantities were measured for 1-mm-long sample sections during tensile testing at $T=23{ }^{\circ} \mathrm{C}$

of the $\gamma$-phase channels between the $\gamma^{\prime}$ particles and formation of cavities at the $\gamma / \gamma^{\prime}$ interfaces.

The specimens in series \#2 fractured at the weld interface, and Fig. 12 illustrates that welding defects in the form of clusters or chains of oxide and carbide nano-particles, as well as fine pores, existing in some areas of the weld interface are likely responsible for the interface weakening and fracture. Indeed, detailed analysis of the microstructure of the fracture regions in the series \#2 specimens shows that cracks responsible for the fracture propagate along the weld interface areas that contain these welding defects or move in the Mar-M247 alloy side (Fig. 12a). No evidence of the crack propagation toward the LSHR side is found. For example, chains of nanometer-sized oxide and carbide particles and pores are clearly seen on both sides of the separated weld interface area (Fig. 12b and c), which is a clear indication that the crack moved through these defects. However, propagation of the crack along the weld interface is arrested as soon as it approaches the interface regions where these welding defects are not present or they are located inside LSHR. In these defectfree weld interface areas the crack moves inside the Mar-M247 alloy (Fig. 12a, c, d). It is interesting to note that when it is inside Mar-M247, the crack tends to propagate outside the fine- grained layer, which is adjacent to the weld interface on the Mar-M247 side, toward the coarser-grained areas. Fractured carbide particles are present on the fracture surface in these areas (Fig. 12d).

Figure 13 shows SEM images of the fracture surface of a tension specimen in series \#2. A circular welding defect covering $\sim 30 \%$ of the fracture surface area is clearly seen (Fig. 13a). Fine carbide and oxide particles coat the surface of this welding defect (Fig. 13b). The fracture surface regions outside this defect show numerous dimples and a refined grain structure of Mar-M247 (Fig. 13b, c).

\section{Discussion}

The LSHR and Mar-M247 Ni-based superalloys used in this work have very different microstructure and mechanical properties, both at room and elevated temperatures (Ref 4). As a result, production of sound welds of these alloys with the use of the IFW process, which relies on the easiness and similarity of the localized plastic flow of the welding materials, is a challenging task. Assessment of the microstructure and 

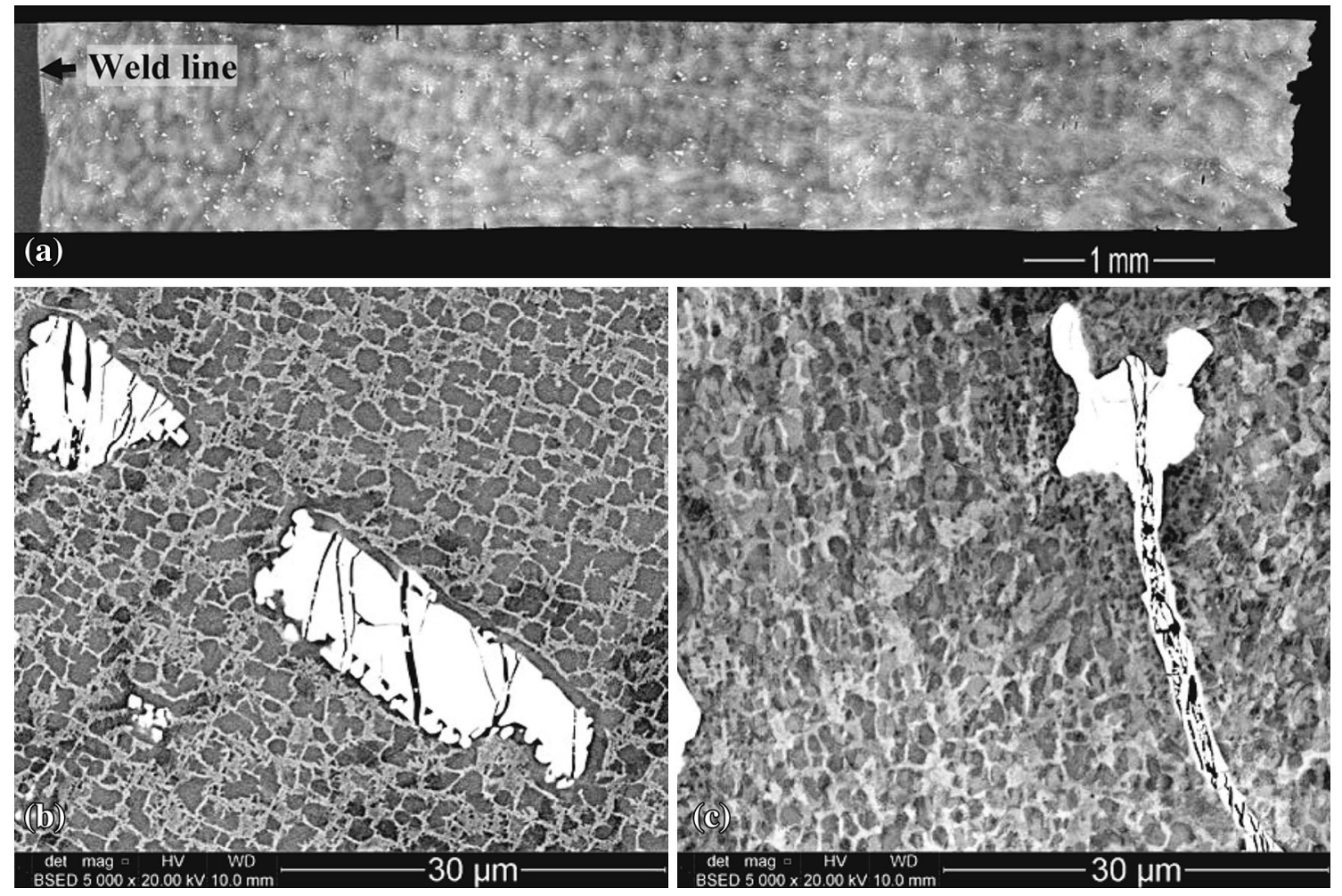

Fig. 8 (a) a BSE image of the longitudinal cross section of the Mar-M247 side of a specimen in series \#1 after tension fracture at room temperature. The weld line is on the left and is shown by an arrow. The jagged fracture surface is on the right. (b, c) The microstructure of the MarM247 side at the distances of (b) $1.0 \mathrm{~mm}$ and (c) $5.0 \mathrm{~mm}$ (near the weld interface) from the fracture surface. The tension axis is horizontal
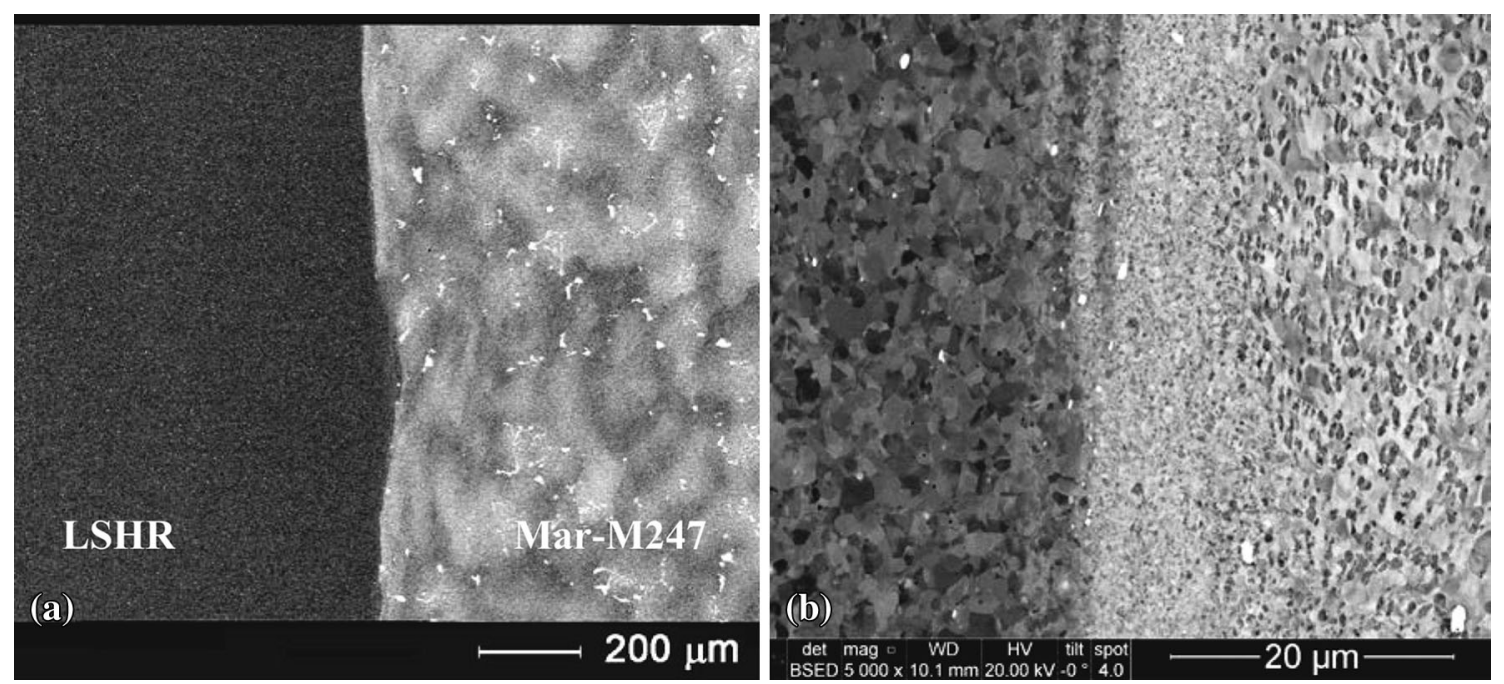

Fig. 9 BSE images of the inertia friction weld interface in a series \#1 specimen: (a) low magnification showing a wavy, defect-free weld interface across the sample thickness; (b) a higher magnification image showing fine-grained structure of LSHR (dark region on the left), coarsegrained structure of Mar-M247 (light region on the right) with fine, round-shaped primary $\gamma^{\prime}$ particles inside the grains, and a thin layer of submicron grains on the Mar-M247 side adjacent to the weld interface. Tensile direction is horizontal

weld quality of the IFW joints, as well as identification of the welding defects and their effect on the weld interface strength, are important tasks needed for optimization of the IFW process for improved properties of the welds.

Heated by friction during the IFW process, the to-be-welded surface of LSHR became soft and easy for plastic flow under both axial and friction stresses. The axial upset forging of the soft layer produced extensive flash protruded far beyond the initial diameter on the LSHR side. On the other hand, at the same IFW conditions, Mar-M247 showed strong resistance to plastic flow and only small plastic extension beyond the initial diameter was observed at the weld region of the Mar-M247 side 
(Ref 13). Although the IFW process took only few seconds, friction-induced heating of the contact surfaces followed by post-weld heat dissipation produced HAZ, which thickness was

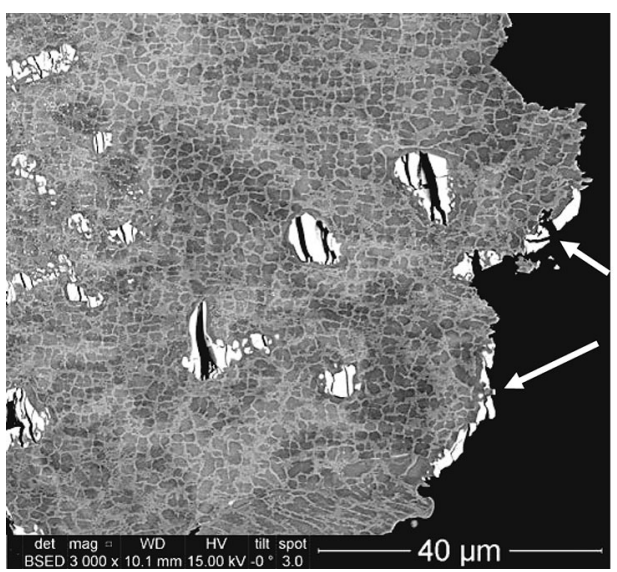

Fractured carbide particles

Fig. 10 BSE image of the longitudinal cross section of specimen $\# 1$ at the fracture surface. The tension axis is horizontal about $\sim 2.5 \mathrm{~mm}$ on the LSHR side and $\sim 3.5-4 \mathrm{~mm}$ on the MarM247 side. Inside the HAZ, both alloys were stronger than their initial conditions. An increase in the microhardness, tensile strength, and strain hardening coefficient with a decrease in the distance from the weld interface inside HAZ coincided with $\gamma$ grain refinement and dissolution of primary $\gamma^{\prime}$ particles. It was therefore suggested that the alloy strengthening inside HAZ was caused by dissolution of primary $\gamma^{\prime}$ particles upon heating during IFW and subsequent re-precipitation of finer $\gamma^{\prime}$ from the super-saturated solid solution during the cooling step, as well as grain refinement. A thinner HAZ on the LSHR side can be explained by a more extensive local upset of this side, relative to Mar-M247 side, during which considerable volume of the heat-affected LSHR region moved to the flash during IFW. Different compositions and initial microstructure conditions of the LSHR and Mar-M247 alloy samples could also contribute to the different responses of these alloys during the IFW-induced heating-cooling events.

Detailed microstructure analysis and results of tension testing, both at RT and $704{ }^{\circ} \mathrm{C}$, of the welded LSHR/MarM247 samples showed that the IFW process is capable of producing defect-free weld joints with the fracture strength
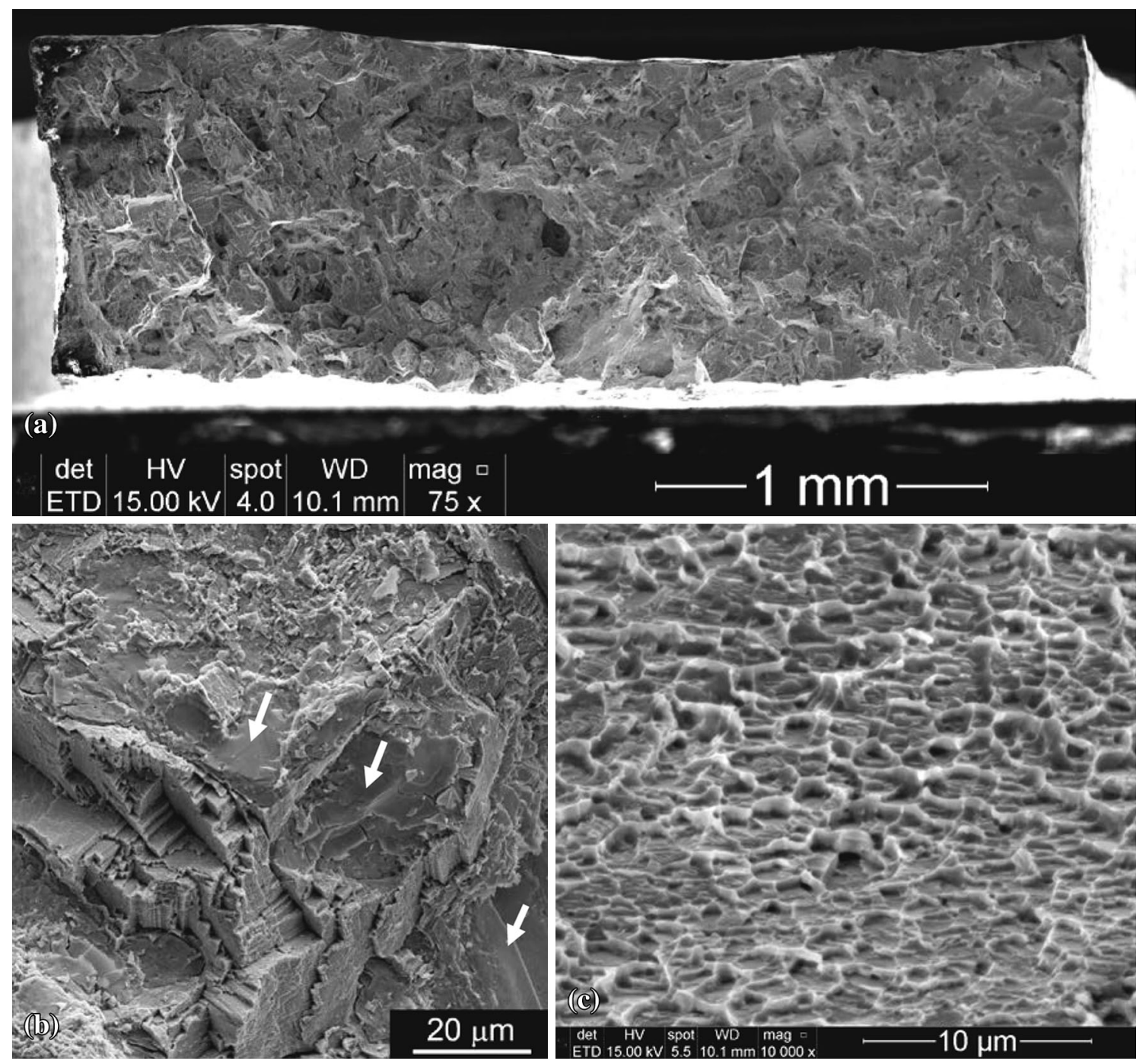

Fig. 11 (a) Fracture surface of a specimen of series \#1 fractured in Mar-M247 region $\sim 6 \mathrm{~mm}$ apart from the weld interface. (b-c) Higher magnification images illustrating (b) a blocky, faceted appearance of fracture and (c) shallow dimples on the faceted surfaces 

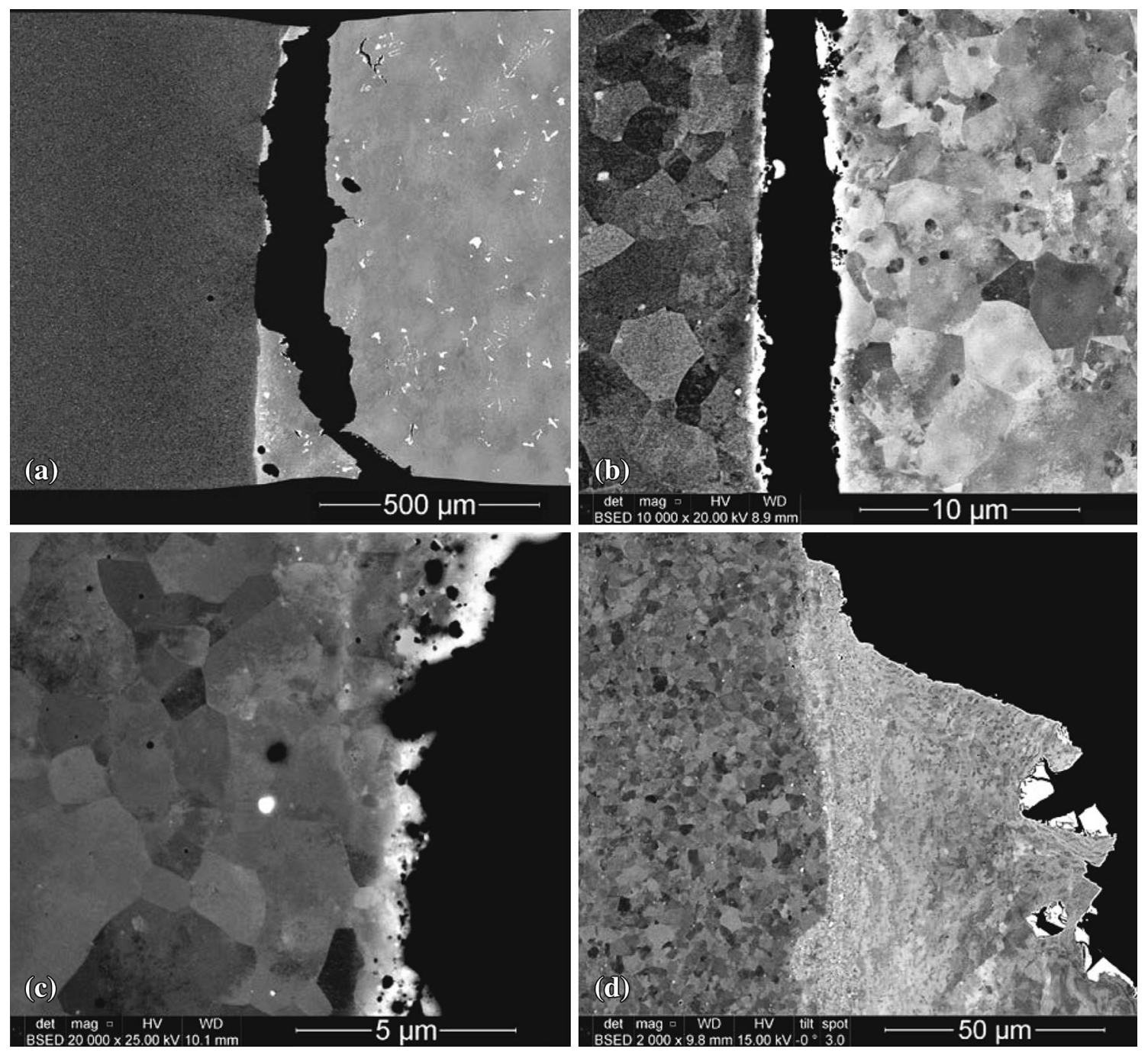

Fig. 12 BSE images of the longitudinal cross section of tension specimen \#2 in the fracture surface region. (a) two adjacent pieces of the fractured sample; (b) fracture region along the flat weld interface; (c) a chain of nanometer-sized oxide and carbide particles and pores along the fracture surface; (d) a part of the sample with a defect-free weld interface, where fracture occurred in the Mar-M247 side outside the fine-grained layer. The LSHR alloy is on the left side from the weld interface and it is darker than the Mar-M247 alloy, which is on the right side. The tension axis is horizontal

higher than the ultimate tensile strength of the parent MarM247 alloy. At both temperatures, tensile plastic deformation of the welded samples occurred only on the Mar-M247 side, because the yield strength of LSHR was much higher than the ultimate tensile strength of Mar-M247 (Table 2). As a result, total elongation of the welded specimens was approximately half of that of Mar-M247 side. Moreover, due to higher hardness and strength of the HAZ region, plastic deformation of the Mar-M247 side localized outside the HAZ and the local strain rapidly decreased to zero with a decrease in the distance from the weld interface. Such distribution of the local plastic strains, as well as strong strain hardening response of the HAZ region, is believed to be beneficial for service performance, as this discourages development of plastic constraints and fracture-initiating deformation defects at the weld interface of these two dissimilar alloys. High strength of the LSHR/Mar-M247 weld joints was also recognized by the facture behavior during tensile testing. Namely, fracture of the samples without welding defects always occurred on the Mar-M247 side outside HAZ, by ductile propagation of cracks initiated inside large carbide particles.

Unfortunately, welding defects present in the rim regions of the weld interface in the form of clusters or chains of nanometer-sized carbide and oxide particles and pores weakened the weld joints in these regions. It was shown in our previous work (Ref 13) that these oxide/carbide nano-particles were formed during the IFW process by frictional milling of carbides and oxides present at the mating surfaces of the alloys, and they accumulated in the rim regions due to insufficient radial plastic flow of the Mar-M247 alloy. These welding defects prohibited strong bonding between the alloys and were the crack initiation sources during tensile testing. The detrimental effect of oxide film on the quality of IFW of dissimilar alloys was reported earlier ( $\operatorname{Ref} 24,25)$. The tensile samples fractured at or near the weld interface when the welding defects were present in noticeable amount. It is however important to point out that the cracks initiated at the weld interface containing the welding defects always failed to propagate in 

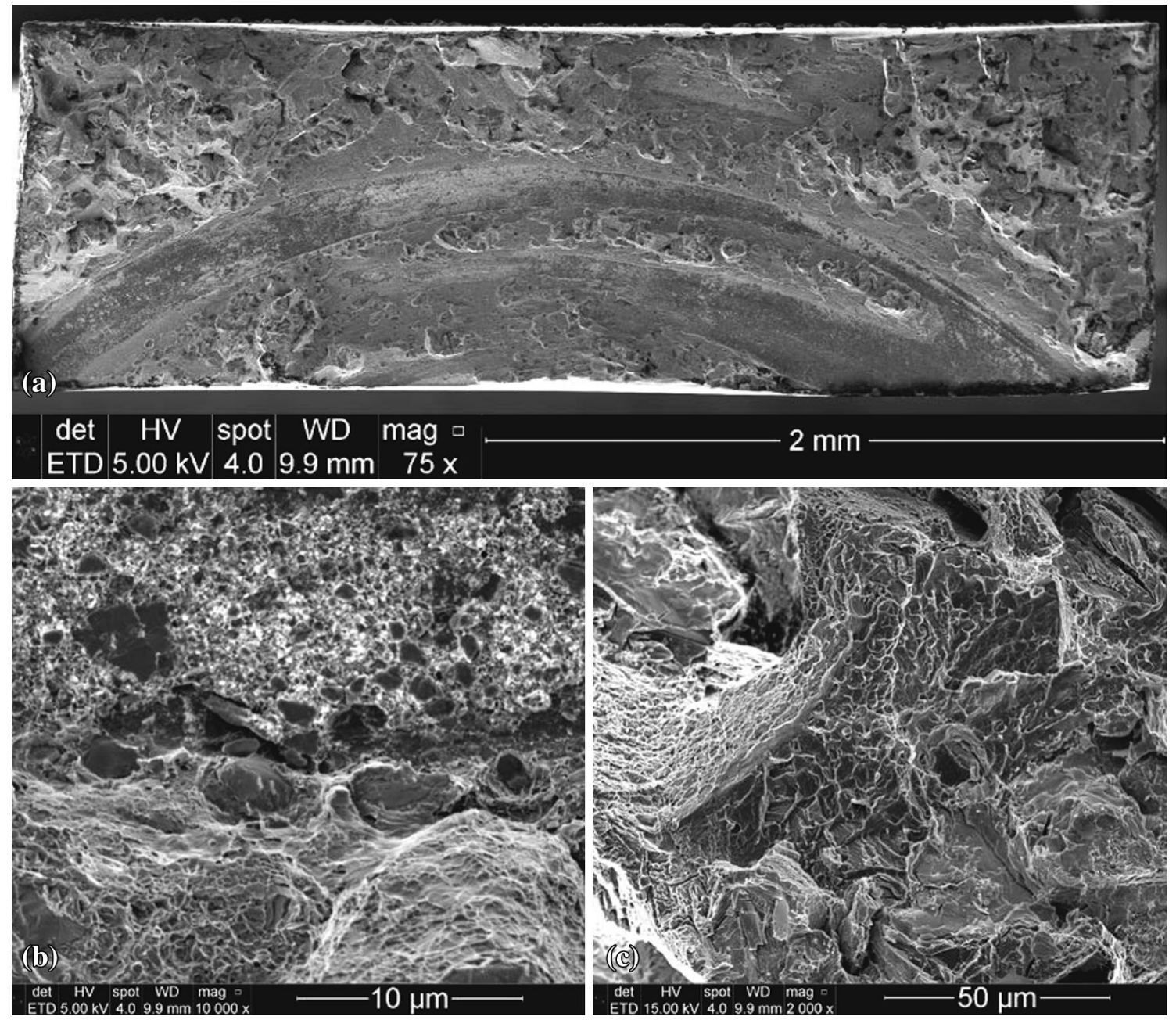

Fig. 13 (a) Fracture surface of a specimen of series \#2 fractured at the weld interface. (b-e) Higher magnification images illustrating (b) fine carbide and oxide particles inside the welding defect (top) and transition to ductile fracture of the Mar-M247 alloy (bottom), (c) facets and dimples outside the welding defect

the weld interface regions where these defects were absent. Instead, these cracks moved toward the Mar-M247 side, far away from the weld interface. Such fracture behavior of the welded specimens reveals that the effective fracture strength of the defect-free weld interface, $\sigma_{\mathrm{f}}^{\text {eff }}$, is above the $\sigma_{\mathrm{u}}$ value of the Mar-M247 alloy. Taking into account that a tensile specimen with the area fraction of the welding defects of $~ 30 \%$ fractured at $\sigma_{\mathrm{u}}=850 \mathrm{MPa}$ (Table 3 ) and assuming that only the defectfree areas of the weld interface were loaded at the end of the tension testing, the effective axial fracture strength of these defect-free interface areas is roughly estimated to be $\sigma_{\mathrm{f}}^{\text {eff }}=1214 \mathrm{MPa}$. The estimated $\sigma_{\mathrm{f}}^{\text {eff }}$ value is higher than $\sigma_{\mathrm{u}}$ of Mar-M247 and even higher than $\sigma_{0.2}$ of LSHR, see Table 2. Such high strength is evidently caused by the refined microstructure of the defect-free weld interface regions. This analysis confirms that the IFW process can provide strong bonding between LSHR and Mar-M247 if clusters of oxide/carbide nano-particles are not formed. The IFW conditions, as well as pre-welding heat treatment of the parent alloys, should be optimized in order to achieve extensive localized radial plastic flow of both alloys at the weld surfaces during the IFW process. The extensive radial plastic flow will flush the joining surfaces from the clusters of oxide and carbide nano-particles and result in a defect-free weld interface.

\section{Summary and Conclusions}

Microstructure, tensile properties, and fracture behavior of the inertia friction weld (IFW) joints of dissimilar superalloys, cast Mar-M247 and wrought LSHR, were studied to assess the weld quality. Tensile tests were conducted at RT and at $704{ }^{\circ} \mathrm{C}$ on the samples containing different areas of the weld interface of the same welded material. The stress-strain curves were registered at different axial distances from the weld interface, with the spatial resolution of $1 \mathrm{~mm}$. Extensive localization of plastic deformation occurred on the Mar-M247 side, outside the HAZ. Inside HAZ, the local plastic strain decreased while the yield strength and strain hardening coefficient of Mar-M247 increased with a decrease in the distance from the weld interface. The LSHR side deformed only elastically. Fracture of the tensile samples occurred in the strain localization region outside HAZ (series \#1) or at/near the weld interface (series 
\#2). Detailed microstructure analysis showed that the samples of series \#1 did not have welding defects and their fracture occurred by ductile propagation of cracks initiated inside large carbide particles through the matrix. The samples of series \#2 contained clusters of nanometer-sized oxide and carbide particles and pores at the weld interface, and cracks were initiated at these defects. However, these cracks did not propagate into the defect-free weld interface areas. Instead, they moved to the Mar-M247 side and final fracture of the samples of series \#2 occurred inside Mar-M247.

The obtained results indicate that the IFW process can provide strong bonding between LSHR and Mar-M247. However, fine carbide and oxide particles agglomerated in several sections of the joined surfaces are the main obstacles for sound welding. Optimization of the IFW process aiming at the softening and improving radial plastic flow of the Mar-M247 alloy during IFW is required.

\section{Acknowledgments}

Numerous discussions with Suresh Babu, Shesh Srivatsa, Jaimie Tiley, Gopal Viswanathan, and William Musinski are appreciated. The inertia friction welding was conducted at the Edison Welding Institute, Columbus, Ohio. Technical support from Jerry Gould and David Workman, EWI, is recognized. Work of ONS was financially supported through the Air Force on-site contract FA8650-10-D-5226 managed by UES, Inc., Dayton, Ohio.

\section{References}

1. D.M. Dimiduk and J.H. Perepezko, Mo-Si-B Alloys: Developing a Revolutionary Turbine-Engine Material, MRS Bull., 2003, 28, p 639645

2. S. Walston, A. Cetel, R. MacKay, K. O'Hara, D. Duhl, and R. Dreshfield, Joint Development of a Fourth Generation Single Crystal Superalloy, Superalloys 2004, K.A. Green, Ed., TMS, Warrendale, 2004, p 15-24

3. J. Hurst, Materials and Structures Research for Gas Turbine Applications Within the NASA Subsonic Fixed Wing Project, NASA/TM2011-216747, NASA GRC, Cleveland, 2011

4. T.P. Gabb, R.A. MacKay, S.L. Draper, C.K. Sudbrack, and M.V. Nathal, The Mechanical Properties of Candidate Superalloys for a Hybrid Turbine Disk, NASA/TM-2013-217901, Cleveland, 2013

5. J.N. DuPont, Welding of Nickel-Based Alloys for Energy Applications, Weld. J. Res. Suppl., 2014, 93(2), p 31s-45s

6. M. Maalekian, Friction Welding - Critical Assessment of Literature, Sci. Technol. Weld. Join., 2007, 12, p 708-729

7. M. Preuss, J.W.L. Pang, P.J. Withers, and G.J. Baxter, Inertia Friction Welding Nickel-Based Superalloys: Part II. Residual Stress Characterization, Metall. Mater. Trans., 2002, 33, p 3227-3234
8. M. Preuss, P.J. Withers, and G.J. Baxter, A Comparison of Inertia Friction Welds in Three Nickel Base Superalloys, Mater. Sci. Eng. A, 2006, 437, p 38-45

9. Z.W. Huang, H.Y. Li, M. Preuss, M. Karadge, P. Bowen, S. Bray, and G. Baxter, Inertia Friction Welding Dissimilar Nickel-Based Superalloys Alloy 720Li ti IN718, Metall. Mater. Trans A, 2007, 38, p 16081620

10. F. Daus, H.Y. Li, G. Baxter, S. Bray, and P. Bowen, Mechanical and Microstructural Assessments of RR1000 to IN718 Inertia Welds-Effect of Welding Parameters, Mater. Sci. Technol., 2007, 23, p 14241432

11. M.Y. Amegadzie, O.T. Ola, O.A. Ojo, P. Wanjara, and M.C. Chaturvedi, On Liquation and Liquid Phase Oxidation During Linear Friction Welding of Nickel-Base IN 738 and CMSX 486 Superalloys, Superalloys 2012, E.S. Huron, R.C. Reed, M.C. Hardy, M.J. Mills, R.E. Montero, P.D. Portella, J. Telesman, Eds., TMS, Materials Park, 2012, p 587-594

12. M. Sakaguchi, A. Sano, T.H. Tran, M. Okazaki, and M. Sekihara, Low Cycle and Thermo-Mechanical Fatigue of Friction Welded Dissimilar Superalloy Joint, J. Sol. Mech. Mater. Eng., 2008, 2, p 1508-1516

13. O.N. Senkov, D.W. Mahaffey, S.L. Semiatin, and C. Woodward, Inertia Friction Welding of Dissimilar Superalloys Mar-M247 and LSHR, Metall. Mater. Trans. A., 2014, 45, p 5545-5561

14. D. Rice, P. Kantzos, B. Hann, J. Neumann, and R. Helmink, P/M Alloy $10-\mathrm{A} 700^{\circ} \mathrm{C}$ Capable Nickel-Based Superalloy for Turbine Disk Applications, Superalloys 2008, R.C. Reed, K.A. Green, P. Caron, T.P. Gabb, M.G. Fahrmann, E.S. Huron and S.A. Woodard, Eds., TMS, Materials Park, 2008, p 139-147

15. T.P. Gabb, J. Gayda, P.T. Kantzos, T. Biles, and W. Konkel, The Tensile Properties of Advanced Nickel-Based Disk Superalloys During Quenching Heat Treatments, NASA/TM-2001-211218, NASA Glenn Research Center, Cleveland, 2001

16. J.R. Kattus, Ni-Base Alloys: Mar-M-247 (Code 4218), Aerospace Structural Metals Handbook, Purdue Research Foundation, West Lafayette, 1999

17. S.L. Semiatin, K.E. MacClary, A.D. Rollett, C.G. Roberts, E.J. Payton, F. Zhang, and T.P. Cabb, Plastic Flow and Microstructure Evolution during Thermomechanical Processing of a PM Nickel-Base Superalloy, Metall. Mater. Trans. A, 2013, 44, p 2778-2798

18. P.R.A.A. Silva, R. Baldan, C.A. Nunes, C.C. Caelho, and A.M.S. Costa, Solution heat-treatment of Nb-modified MAR-M247 superalloy, Mater. Charact., 2013, 75, p 214-219

19. V.I. Vill, Friction Welding of Metals, American Welding Society, New York, 1962

20. Standard Methods for Mechanical Testing of Welds: ANSI/AWS B 4.0. American Welding Society, Miami, 2007

21. M.J. Donachie and S.J. Donachie, Superalloys: A Technical Guide, 2nd ed., ASM International, Materials Park, 2002

22. ASM Handbook Vol. 12, Fractography, ASM Internat., Materials Park, 1987, p 389-395

23. S.K. Bhaumik, T.A. Bhaskaran, R. Rangaraju, M.A. Venkataswamy, M.A. Parameswara, and R.V. Krishnan, Failure of Turbine Rotor Blisk of an Aircraft Engine, Eng. Fail. Anal., 2002, 9, p 287-301

24. Kh.G. Schmitt-Thomas and R. Siede, Flywheel Friction Welding of Nickel Base Superalloys of Different Hot Ductility, International Conference on Quality and Reliability of Welding, Vol. 4, Chinese Mech. Eng. Soc., 1984, p D.8.1-D.8.6

25. Z. Li, C. Maldonado, T.H. North, and B. Altshuller, Mechanical and Metallurgical Properties of MMC Friction Welds, Weld. Res. Suppl., 1997, 76, p 367s-373s 